\title{
The Hypoglycemic Effect of the Kelp on Diabetes Mellitus Model Induced by Alloxan in Rats
}

\section{Shao-Hua Long ${ }^{1}$, Zhu-Qin Yu ${ }^{1}$, Li Shuai ${ }^{2}$, Yun-Liang Guo ${ }^{1, *}$, De-Lin Duan ${ }^{3}{ }^{*}$, Xin-Ying Xu ${ }^{1}$ and Xiao-Dan $\mathrm{Li}^{1}$}

1 Institute of Cerebrovascular Diseases, Affiliated Hospital, Qingdao University Medical College, Qingdao Shandong 266003, China; E-Mails: long121400@163.com(S.-H.L.); yuzhuq2008@163.com (Z.-Q.Y.); guoqdsd@163.com (X.-Y.X.); zongshiyi@163.com (X.-D.L.)

2 School of Chemistry, Chemical Engineering and Environmental Sciences, Qingdao University, Qingdao Shandong 266071, China; E-Mail: shuailitunicat@yahoo.com.cn Institute of Oceanology, Chinese Academy of Sciences, Qingdao 266071, China

* Authors to whom correspondence should be addressed; E-Mails: guoqdsd@ yahoo.com.cn (Y.-L.G.); dlduan@qdio.ac.cn (D.-L.D.); Tel.: +86-0532-829-115-23 (Y.-L.G.); +86-0532-828-985-56 (D.-L.D.); Fax: +86-0532-829-118-40 (Y.-L.G.); +86-0532-828-985-56 (D.-L.D.).

Received: 25 November 2011; in revised form: 3 February 2012 / Accepted: 8 February 2012 / Published: 12 March 2012

Abstract: Hypoglycemic effects and the use of kelp in diabetes mellitus (DM) model rats induced by alloxan were investigated. Sixty healthy male rats were used to establish DM models by injecting alloxan intraperitoneally. Kelp powder was added to the general forage for the rats. The levels of fasting blood glucose (FBG) were determined by an automatic blood glucose device. Electrochemiluminescence immunoassay was applied to determine the serum levels of insulin. The serum levels of malondialdehyde (MDA) were measured by thiobarbituric acid assay and nitric oxide (NO) by nitrate reductase assay. The activities of superoxide dismutase (SOD) were determined by xanthinoxidase assay and glutathione peroxidase (GSH-Px) by chemical colorimetry. The shape and structure of islet cells were observed with Hematine-Eosin staining, and the expression of superoxide dismutase (SOD) and inducible nitric oxide synthase (iNOS) in islet cells were detected by immunohistochemical assay. The results showed that the serum levels of insulin after treatment with kelp powder increased significantly compared to those in the DM-model group, while the FBG in the medium-high dose treated groups decreased significantly compared to those in the DM-model group $(P<0.05)$. The levels of MDA and NO in the kelp powder groups were lower than those in the DM-model group, while the activities of 
SOD and GSH-Px were higher than those in the DM-model group, of which a significant difference existed between the medium-high dose treated groups and the DM-model group $(P<0.05)$. The shape and structure of islet cells improved with the up-expressing SOD and down-expressing iNOS in the medium-high dose treated groups compared to those in the DM-model group $(P<0.05)$. There were no significant differences between the medium and high dose treated groups, all above indexes $(P>0.05)$. It is suggested that kelp might aid recovery of the the islet cell secreting function and reduce the level of FBG by an antioxidant effect.

Keywords: kelp; diabetes mellitus; alloxan; oxidative stress; rats

\section{Introduction}

Diabetes mellitus (DM) is a common disease in the world and type $2 \mathrm{DM}$ accounts for about $90 \%-95 \%$ of cases. Although the etiology of type $2 \mathrm{DM}$ is complex and its pathogenesis is not completely understood, the disease is associated with the level of free radicals and the antioxidant system dysfunction. It has been well established that oxidative stress is a commonly used approach to DM and its complications [1]. Malondialdehyde (MDA) can reflect oxygen free radicals (OFR) in the body that are produced when OFR oxidizes polyunsaturated fatty acids in bio-membranes [2]. The gas free radical, nitric oxide (NO), is important in initiating type $2 \mathrm{DM}$, insulin resistance and secondary effects as well as the islet beta cell function obstacle [3,4]. The natural enzyme superoxide dismutase (SOD) can capture free radicals in the body and the catalytic oxidation enzyme glutathione peroxidase (GSH-Px) is widespread in the body. These enzymes work to eliminate OFR in the body when decline in activity leads to OFR accumulation [5,6].

Laminaria japonica (L. japonica) is a widely cultivated kelp, with China being the largest producer [7]. In China, the kelp is used for food in daily life and also used in traditional medicine. According to the "Compendium of Materia Medica" [8], kelp is cold, salty, has efficacy in clearing water, is soft, firm, dissipating and can dissolve phlegm [9], as well as alleviate edema,and eliminate carbuncle. Kelp belongs to the Phaeophyta Laminariaceae Laminaria, containing laminarin, ammonium alginate, mannitol, vitamins, amino acids and various normal and trace elements, with a variety of 40 active components [10]. The variety of physiological functions of the kelp relate to the biological activity of polysaccharides which can improve the immunity function, anti-aging, anti-tumor [11], anti-atheroscloresis, anti-diabetics [12,13] and other such biological activity. Until now, there has been only limited research and reports on L. japonica's anti-diabetic functions and mechanism [14]. Therefore, the experiment described in this paper expands the exploration of the hypoglycemic effect along with a possible mechanism of the effect of kelp on alloxan-induced diabetic rats. 


\section{Results and Discussion}

\subsection{General Situation}

Before alloxan was injected, all rats reacted nimbly, had hair that was bright and smooth and there was no significant variation in body weights $(F=0.05, q=0.03-0.55, P>0.05)$. After alloxan was injected and before kelp powder, forage was administered, and the animals showed typical signs of diabetes mellitus: clumsiness, slow actions, dull colored fur and marasmus. Average body weights reduced significantly before alloxan was injected $(F=1643.22, q=21.77-104.53, P<0.05)$ and there was no significant difference between the weights of kelp-treated rats and DM-model rats $(P>0.05)$.

After kelp powder forage was administered, the action and hair color of animals in kelp treated and DM-model groups recovered gradually, with body weight becoming significantly higher than before treatment, lower than that of the control group $(F=149.29, q=22.82-29.00, P<0.05)$. Average body weight of animals in the DM-model and kelp-treated groups was significant lower than that in the control group $(F=149.29, q=22.82-30.06, P<0.05)$. There was no significant difference between the low-dose group and DM-model rats $(P>0.05)$. Average body weight of animals in the medium-dose and high-dose groups was significantly higher than in the DM-model rats $(P<0.05)$, but there was no significant difference between medium-dose and high-dose groups $(P>0.05)$ (Table 1).

Table 1. The average body weights of animals in the experiment $(\bar{x} \pm \mathrm{s}$, Unit: g).

\begin{tabular}{cccccc}
\hline Groups & $\mathbf{n}$ & Dose & $\begin{array}{c}\text { Before } \\
\text { experiment }\end{array}$ & $\begin{array}{c}\text { Before } \\
\text { kelp-treated }\end{array}$ & After kelp-treated \\
\hline Control group & 10 & General forage & $151.76 \pm 3.45$ & $168.50 \pm 4.22$ & $189.69 \pm 4.55$ \\
DM-model group & 10 & General forage & $151.85 \pm 3.67$ & $133.62 \pm 5.35^{\mathrm{a}}$ & $139.46 \pm 5.36$ \\
Low-dose group & 10 & $1.25 \mathrm{~g} / \mathrm{kg} \mathrm{kelp}$ & $151.68 \pm 3.38$ & $134.46 \pm 5.23^{\mathrm{a}}$ & $141.24 \pm 5.32^{\mathrm{bc}}$ \\
Medium-dose group & 10 & $5.0 \mathrm{~g} / \mathrm{kg} \mathrm{kelp}$ & $152.26 \pm 3.51$ & $135.27 \pm 5.18^{\mathrm{a}}$ & $150.24 \pm 5.45^{\mathrm{b}, \mathrm{c}, \mathrm{d}}$ \\
High-dose group & 10 & $12.5 \mathrm{~g} / \mathrm{kg} \mathrm{kelp}$ & $151.65 \pm 3.43$ & $133.55 \pm 5.27^{\mathrm{a}}$ & $151.56 \pm 5.67^{\mathrm{b}, \mathrm{c}, \mathrm{d}}$ \\
\hline${ }^{\mathrm{a}} P<0.05$ vs. before experiment; ${ }^{\mathrm{b}} P<0.05$ & $v s$. before kelp-treated; ${ }^{\mathrm{c}} P<0.05$ vs. DM-model group; \\
${ }^{\mathrm{d}} P<0.05 \mathrm{vs.} \mathrm{low-dose} \mathrm{group.}$ & & &
\end{tabular}

\subsection{The Level of Fasting Blood Glucose (FBG)}

Before injecting alloxan, there were no obvious differences in FBG levels among the control group, DM-model rats and kelp-treated groups $(F=0.05, q=0.03-0.55, P>0.05)$. After injecting alloxan and before administering kelp powder forage, FBG levels increased significantly compared to those of DM-model rats and the control group $(F=79.52, q=19.68-20.19, P<0.05)$. There was no significant difference between kelp-treated groups and DM-model rats $(P>0.05)$.

After administering kelp powder forage, FBG levels in kelp-treated groups were significantly lower than in the DM-model rats and higher than in the control group $(F=189.19, q=9.24-36.44$, $P<0.05)$. After the experiment, FBG levels in the DM-model rats and kelp-treated groups were significantly higher than in the control group $(F=188.99, q=9.20-36.41, P<0.05)$. There was no significant difference between the low-dose group and DM-model rats $(P>0.05)$. FBG levels in the medium-dose group and high-dose group were significantly lower than in the DM-model rats $(P<0.05)$ but there was no significant difference between the medium-dose group and the high-dose 
group $(P>0.05)$. Results indicated that medium-dose kelp could achieve an ideal hypoglycemic effect (Table 2).

Table 2. The levels of fasting blood glucose (FBG) in the experiment $(\bar{x} \pm \mathrm{s}, \mathrm{mmol} / \mathrm{L})$.

\begin{tabular}{lccccc}
\hline \multicolumn{1}{c}{ Groups } & $\mathbf{n}$ & Dose & $\begin{array}{c}\text { Before } \\
\text { experiment }\end{array}$ & $\begin{array}{c}\text { Before } \\
\text { kelp-treated }\end{array}$ & $\begin{array}{c}\text { After } \\
\text { kelp-treated }\end{array}$ \\
\hline Control group & 10 & General forage & $4.78 \pm 0.39$ & $4.95 \pm 0.34$ & $4.97 \pm 0.33$ \\
DM-model group & 10 & General forage & $4.82 \pm 0.33$ & $17.86 \pm 2.26^{\mathrm{a}}$ & $13.32 \pm 1.40^{\mathrm{b}}$ \\
Low-dose group & 10 & $1.25 \mathrm{~g} / \mathrm{kg}$ kelp & $4.55 \pm 0.35$ & $18.12 \pm 2.28^{\mathrm{a}}$ & $12.63 \pm 1.67^{\mathrm{b}}$ \\
Medium-dose group & 10 & $5.0 \mathrm{~g} / \mathrm{kg}$ kelp & $4.81 \pm 0.37$ & $17.79 \pm 2.31^{\mathrm{a}}$ & $9.37 \pm 1.70^{\mathrm{b}, \mathrm{c}, \mathrm{d}}$ \\
High-dose group & 10 & $12.5 \mathrm{~g} / \mathrm{kg}$ kelp & $4.65 \pm 0.34$ & $18.05 \pm 2.35^{\mathrm{a}}$ & $9.18 \pm 1.65^{\mathrm{b}, \mathrm{c}, \mathrm{d}}$ \\
\hline${ }^{\mathrm{a}} P<0.05$ vs. before experiment; ${ }^{\mathrm{b}} P<0.05$ & vs. before kelp-treated; ${ }^{\mathrm{c}} P<0.05$ vs. DM-model group; \\
${ }^{\mathrm{d}} P<0.05$ vs. low-dose group. & & & &
\end{tabular}

\subsection{The Serum Level of Insulin}

The serum levels of insulin in the DM-model group $(11.23 \pm 3.45, \mathrm{pmol} / \mathrm{L})$ were significantly lower than in the control group $(71.38 \pm 15.26$, pmol/L), while those in kelp-treated groups were significantly higher than those in the DM-model group $(F=13.250, q=5.12-9.73, P<0.05)$, but there were no significant differences between high-dose $(26.22 \pm 4.85$, pmol/L), medium-dose $(24.17 \pm 5.09, \mathrm{pmol} / \mathrm{L})$ and low-dose $(18.78 \pm 4.56$, pmol/L) groups $(P>0.05)$.

\subsection{The Levels of MDA and NO and the Activities of SOD and GSH-PX}

Serum levels of MDA and NO were significantly higher and actions of SOD and GSH-Px were sharply lower in the DM-model rats and kelp-treaded groups than in the control group $(F=12.60$, $q=3.72-7.17, P<0.05)$. MDA and NO serum levels were significantly lower and actions of SOD and GSH-PX were higher in medium-dose and high-dose groups than in DM-model groups $(P<0.05)$. There was no significant difference between medium-dose and high-dose groups $(P>0.05)$. Results indicated that medium-dose kelp could achieve ideal anti-oxidant effect (Table 3).

Table 3. The levels of malondialdehyde (MDA) and nitric oxide (NO) and the activities of superoxide dismutase (SOD) and glutathione peroxidase (GSH-Px) in the experiment $(\bar{x} \pm \mathrm{s})$.

\begin{tabular}{ccccccc}
\hline Groups & $\mathbf{n}$ & Dose & MDA $(\mathbf{m m o l} / \mathbf{L})$ & $\mathbf{N O}(\boldsymbol{\mu m o l} / \mathbf{L})$ & $\mathbf{S O D}(\mathbf{U} / \mathbf{m L})$ & $\mathbf{G S H}-\mathbf{P x}(\mathbf{U} / \mathbf{m L})$ \\
\hline Control group & 10 & General forage & $7.15 \pm 0.68$ & $14.96 \pm 1.56$ & $156 \pm 14.02$ & $922 \pm 22.16$ \\
DM-model group & 10 & General forage & $9.38 \pm 1.24^{\mathrm{a}}$ & $23.86 \pm 2.17^{\mathrm{a}}$ & $122 \pm 11.26^{\mathrm{a}}$ & $828 \pm 15.46^{\mathrm{a}}$ \\
Low-dose group & 10 & $1.25 \mathrm{~g} / \mathrm{kg} \mathrm{kelp}$ & $8.93 \pm 1.02$ & $21.50 \pm 2.24$ & $127 \pm 18.35$ & $837 \pm 24.82$ \\
Medium-dose group & 10 & $5.0 \mathrm{~g} / \mathrm{kg} \mathrm{kelp}$ & $8.02 \pm 0.45^{\mathrm{b}, \mathrm{c}}$ & $17.13 \pm 1.41^{\mathrm{b}, \mathrm{c}}$ & $143 \pm 22.26^{\mathrm{b}, \mathrm{c}}$ & $890 \pm 24.58^{\mathrm{b}, \mathrm{c}}$ \\
High-dose group $^{\mathrm{a}}$ & 10 & $12.5 \mathrm{~g} / \mathrm{kg} \mathrm{kelp}$ & $7.83 \pm 0.51^{\mathrm{b}, \mathrm{c}}$ & $16.32 \pm 1.73^{\mathrm{b}, \mathrm{c}}$ & $145 \pm 19.38^{\mathrm{b}, \mathrm{c}}$ & $886 \pm 25.72^{\mathrm{b}, \mathrm{c}}$ \\
\hline${ }^{\mathrm{a}} \boldsymbol{P}<0.05$ vsrsus control group; ${ }^{\mathrm{b}} P<0.05$ versus DM-model group; ${ }^{\mathrm{c}} P<0.05$ versus low-dose group.
\end{tabular}

\subsection{Pancreatic Islets Tissue Pathology}

The cells of pancreatic islets in the control group are oval in shape, uniform in size and evenly dispersed in the pancreatic gland bubble. DM-model rats have shrunken islets, a reduced number of 
islet cells that are unevenly dispersed, vacuolar degeneration and karyolysis, etc. but this improved significantly in medium-dose and high-dose kelp-treated groups. The index of pancreatic B cells in medium-dose and high-doses kelp-treated groups is higher than in the DM-model rats (Table 4 and Figure 1).

Table 4. The B cell index and the expressions of SOD and inducible nitric oxide synthase (iNOS) in the panreatic tissue $(\bar{x} \pm \mathrm{s})$.

\begin{tabular}{lccccc}
\hline \multicolumn{1}{c}{ Groups } & n & Dose & B cell index $(\%)$ & SOD $(\mathbf{A})$ & iNOS(A) \\
\hline Control group & 10 & General forage & $61.48 \pm 9.13$ & $0.48 \pm 0.15$ & $0.16 \pm 0.05$ \\
DM-model group & 10 & General forage & $28.16 \pm 5.64^{\mathrm{a}}$ & $0.41 \pm 0.12^{\mathrm{a}}$ & $0.41 \pm 0.12^{\mathrm{a}}$ \\
Low-dose group & 10 & $1.25 \mathrm{~g} / \mathrm{kg} \mathrm{kelp}$ & $31.49 \pm 6.28$ & $0.22 \pm 0.08$ & $0.35 \pm 0.10$ \\
Medium-dose group & 10 & $5.0 \mathrm{~g} / \mathrm{kg} \mathrm{kelp}$ & $45.37 \pm 6.82^{\mathrm{b}}$ & $0.31 \pm 0.10^{\mathrm{b}}$ & $0.24 \pm 0.09^{\mathrm{b}}$ \\
High-dose group & 10 & $12.5 \mathrm{~g} / \mathrm{kg} \mathrm{kelp}$ & $46.71 \pm 7.36^{\mathrm{b}}$ & $0.33 \pm 0.12^{\mathrm{b}}$ & $0.23 \pm 0.08^{\mathrm{b}}$ \\
\hline
\end{tabular}

${ }^{\mathrm{a}} P<0.05$ versus control group; ${ }^{\mathrm{b}} P<0.05$ versus DM-model group.

Figure 1. The comparison of the pancreatic islet cells. $\mathrm{HE} \times 400$, bar $25 \mu \mathrm{m}$. (A) Control group, (B) DM-model group, and (C) Medium-dose kelp-treated group.
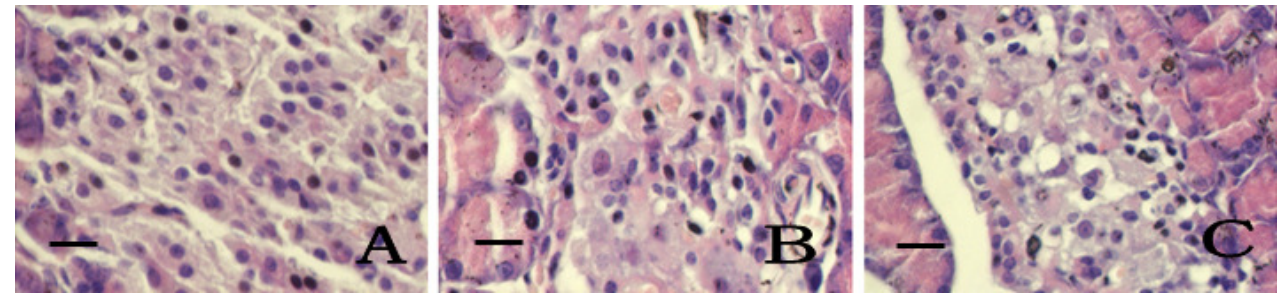

\subsection{Immunohistochemistry of SOD and iNOS}

SOD expression in pancreatic islet cells of control group rats was strong and scattered focally with deep-yellow color. SOD expression was reduced in DM-model rats $(t=7.89, P<0.05)$. In medium-dose and high-dose kelp-treated group rats, SOD expression in islet cells was stronger than that in DM-model rats $(t=4.73-4.76, P<0.05)$. There was no significant difference between the low-dose kelp-treated group and the DM-model rats $(t=1.69, P>0.05)$. (Table 4 and Figure 2$)$.

Figure 2. The expression of inducible nitric oxide synthase (iNOS) in the pancreatic islet cells, SABC $\times$ 400, bar $25 \mu \mathrm{m}$. (A) Control group, (B) DM-model group, and (C) Medium-dose kelp-treated group.

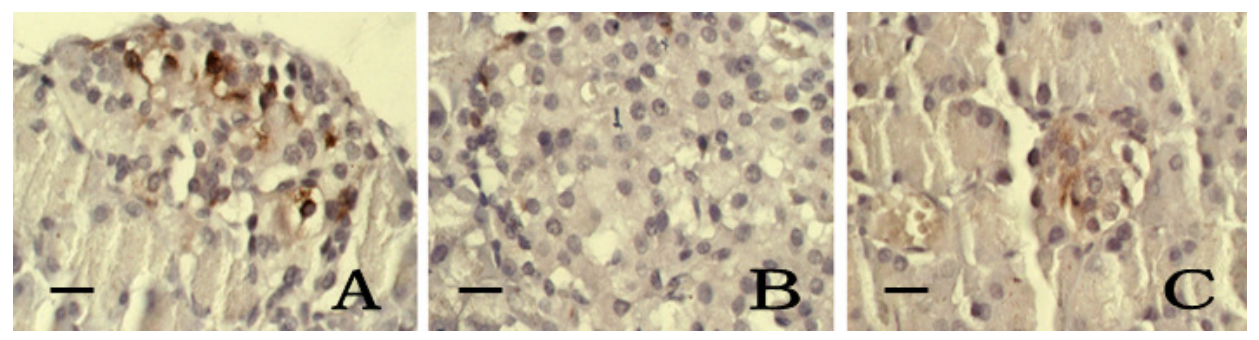

iNOS expression in pancreatic islet cells of control group rats was weak and scattered focally with light-yellow color and was significantly stronger in DM-model rats $(t=8.16, P<0.05)$. In 
medium-dose and high-dose kelp treated group rats, iNOS expression in islet cells was weaker than in the DM-model rats $(t=4.81-5.30, P<0.05)$. There was no significant difference between the low-dose kelp treated group and the DM-model rats $(t=1.90, P>0.05)$. (Table 4 and Figure 3$)$.

Figure 3. The expression of superoxide dismutase (SOD) in the pancreatic islet cells, SABC $\times 400$, bar $25 \mu \mathrm{m}$. (A) Control group, (B) DM-model group, and (C) Medium-dose kelp-treated group.
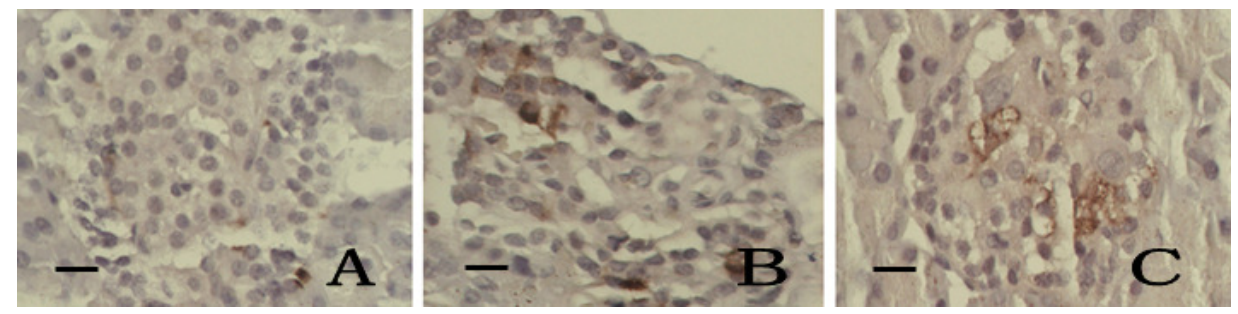

\subsection{Discussion}

Hyperglycemia and oxidative stress are closely related to diabetes mellitus and its complications. The "common soil" theory of Ceriello et al. $[15,16]$ holds that oxidative stress is a common feature of insulin resistance, diabetes mellitus and cerebrovascular diseases [17]. In a body suffering from various harmful stimuli, there is an increase in free radicals and decreased elimination of those radicals can upset the balance of the oxidation system and antioxidant system, and damage tissues and function [18,19]. At the same time, an overflow of oxygen free radicals (OFR) causes lipid peroxidation (LPO), which increases the damage of the oxidative stress through a chain reaction [20,21]. Diabetes mellitus patients with long-term hyperglycemia produce more OFR due to increased glucose autoxidation and protein saccharification, which weakens oxidation resistance and initiates oxidation stress [22]. Increased OFR plays an important role in initiating type 2 diabetes mellitus, insulin resistance and secondary effects, and the islet beta cell function obstacle. It becomes an important media for various factors that cause type 2 diabetes mellitus [23].

Alloxan has a specific toxic effect on islet beta cells that can cause damage by producing a superoxide radical, damage the DNA of the cell and activate polyphosphate ADP ribosomes synthase. This can reduce the coenzyme I, impair mRNA function and cause proinsulin decrease and insulin shortage [24]. In the process of diabetes mellitus development, the anti-oxidant defense level drops and the ability to eliminate free radicals weakens [25,26]. Bottino et al. [27] separated and purified islet cells by using an anti-oxidant to disrupt islet cells at an early stage and found that if blocking oxidative stress reduces damage to the islet cells and promotes their proliferation, it provides a new way of thinking about early diagnosis and intervention for diabetes mellitus. Our previous researches confirmed that kelp has antioxidant effects on the organism and can improve the oxidative stress [12,13].

In this experiment, the serum MDA and NO content in DM-model rats were significantly higher than those in the control group. The action of serum SOD and GSH-Px in DM-model rats was significantly less than in the control group. At the same time, SOD expression in pancreatic islet cells in the DM-model rats was significantly lower and iNOS expression was higher than in the control group. The number of islet cells and beta cells reduced significantly and become partly pyknotic and 
there was necrosis related to a decrease in serum insulin levels as well as increases in fasting blood glucose levels. Such features indicate that diabetes mellitus models, induced by alloxan, caused much lipid peroxidation in the rat body, injured the structure and secretion function of the islet cells and increased fasting blood glucose levels.

After kelp powder was added to interfere with the diabetes mellitus models induced by alloxan, serum levels of MDA and NO decreased significantly and the actions of serum SOD and GSH-Px increased in comparison with the DM-model group. Immunochemical stain showed that SOD expression in pancreatic islet cells was significantly higher and iNOS expression was lower than in the DM-model group. The structure of the pancreatic islet cells in kelp powder treated groups clearly improved in comparison with the DM-model group. Apparently, kelp enhances anti-oxidant enzyme activity, reduces lipid peroxidation (LPO) and products induced by diabetes mellitus and shows an antioxidant effect in the organism. Changes in fasting blood glucose (FBG) levels, serum insulin levels and animal weights show that FBG levels in kelp powder treated groups are significantly lower than in the DM-model group, while serum insulin levels and animal weights were higher than in the DM-model group. Results indicate that kelp could play a hypoglycemic role by enhancing anti-oxidation and enabling recovery of the pancreatic islet cell secreting function.

\section{Experimental Section}

\subsection{The Creation of Diabetic Models}

Sixty SPF grade healthy male Wistar rats weighing 140-160 g were purchased from the Experiment Animal Center of Qingdao Drug Inspection Institute (SCXK (LU) 20090100). Local regulations related to ethical experimentation on animals and guidelines for the care and use of laboratory animals were followed in all animal procedures in this experiment. This experiment was approved by the Ethics Committee of Qingdao University Medical College (No. QUMC 2011-09). Animals were acclimatized for 7 days and allowed free access to food and water at room temperature $\left(23 \pm 2{ }^{\circ} \mathrm{C}\right)$ and humidity-controlled housing with natural illumination. Initially, an extracted blood sample $(0.5 \mathrm{~mL})$ from the tail vein was used for the serum separation and determination of fasting blood glucose (FBG) levels. Subsequently, ten $(\mathrm{n}=10)$ experimental animals were randomized as a control group and injected with equivalent normal saline and the remaining 50 rats were injected intraperitoneally (i.p.) with 1.5\% alloxan (100 mg/kg body weight), once every three days and three times continuously [28,29]. Three days after the final injection, the FBG level was determined and FBG $>15.00 \mathrm{mmol} / \mathrm{L}$ served as the standard in successful diabetes mellitus (DM) models. Ten of the 50 experimental rats were excluded because they did not satisfy the standard. The remaining $40 \mathrm{DM}$-model rats were subjected to experiment and randomly divided into a DM-model group $(\mathrm{n}=10)$, and three kelp treated groups: a low-dose group $(1.25 \mathrm{~g} / \mathrm{kg}, \mathrm{n}=10)$, a medium-dose group $(5.0 \mathrm{~g} / \mathrm{kg}, \mathrm{n}=10)$ and a high-dose group $(12.5 \mathrm{~g} / \mathrm{kg}, \mathrm{n}=10)$. 


\subsection{The General Forage and Kelp Powder Forage}

The main components of the general forage: soybean meal $20.4 \%$, corn flour $31.7 \%$, wheat bran $7.2 \%$, wheat flour $28.8 \%$, fish meal $7.2 \%$, yeast $2.4 \%$, salt $0.2 \%$, bone meal $1.4 \%$, cod liver oil $0.04 \%$, Vitamin E powder $0.04 \%$, milk powder $0.18 \%$, trace elements $0.04 \%$.

"Zhongke No.1" kelp powder forage is derived from kelp products manufactured at the Institute of Oceanology, Chinese Academy of Sciences. Chemical analysis shows the main components to be dietary fiber $26.1 \%$, protein $8.5 \%$, lipid $0.39 \%$, total amino acid $10.49 \mathrm{mg} / 100 \mathrm{~g}$, Vitamin A $273 \mu \mathrm{g} / 100 \mathrm{~g}$, and Vitamin C $3 \mu \mathrm{g} / 100 \mathrm{~g}$.

The kelp powder forage used as an ingredient in the feed for the rats was pressed into a block, air dried and reserved. The low-dose forage contains general forage $97.5 \%$ and kelp powder $2.5 \%$, the medium-dose forage contains general forage $90 \%$ and kelp powder $10 \%$, and the high-dose forage contains general forage $75 \%$ and kelp powder $25 \%$.

\subsection{Inference of Tests}

Rats in the control group and DM-model group were fed with general forage for two weeks. Rats in the kelp-treated groups were fed with kelp powder forage for two weeks.

The low-dose kelp powder $(2.5 \%)$ equals $1.25 \mathrm{~g} / \mathrm{kg}$ body weight per day, the medium-does kelp powder (10\%) equals $5.0 \mathrm{~g} / \mathrm{kg}$ body weight per day and the high-dose kelp powder (25\%) equals $12.5 \mathrm{~g} / \mathrm{kg}$ body weight per day.

\subsection{Preparation of Samples}

3.3.1. Serum preparation. At the end of this experiment, all rats were denied food for $12 \mathrm{~h}$, then FBG was determined and $4 \mathrm{~mL}$ blood was collected from the eye artery using heparinized capillary tubes. Blood samples were centrifuged for 10 minutes at $4000 \mathrm{r} / \mathrm{min}$ to separate serum and then stored at $-20{ }^{\circ} \mathrm{C}$.

3.3.2. Pancreatic tissue. At the end of this experiment, animals were sacrificed by cervical dislocation and pancreatic tissues were immediately collected. Rudimental blood was fully washed with normal saline at $-4{ }^{\circ} \mathrm{C}$, and placed in $4 \%$ formaldehyde for fixing.

\subsection{Index of Determinations}

\subsubsection{FBG Level}

An automatic blood glucose meter (Johnson \& Johnson Medical Equipment Co., Ltd., Germany) and blood glucose test strips (Onetouch, Ultra) were used to detect FBG level (mmol/L).

\subsubsection{The Serum Level of Insulin}

Serum samples were thawed at room temperature and centrifuged again. Electrochemiluminescence immunoassay (ECLIA) was applied to determine the serum level of insulin with Elecsys 2010 and Cobase 411 analyzers and Roche diagnostics reagent kits (12017547). All standards were prepared before starting the assay procedure. The first incubation: insulin from $20 \mu \mathrm{L}$ serum sample, a 
biotinylated monoclonal insulin-specific antibody, and a monoclonal insulin-specific antibody labeled with a ruthenium complex form a sandwich complex. The second incubation: after addition of streptavidin-coated microparticles, the complex becomes bound to the solid phase via interaction of bitin and strepavidin. Then the reaction mixture is aspirated into the measuring cell where the microparticles are magnetically captured onto the surface of the electrode. Unbound substances are then removed with ProCell. A voltage is applied to the electrode to induce chemiluminescent emission which is measured by a photomultiplier. The results are determined via a calibration curve which is instrument-specifically generated by 2-point calibration and a master curve provided via the reagent barcode. Finally, the analyzer automatically calculates the analyte concentration of each sample. The measuring range of the assay is $1.39-6945 \mathrm{pmol} / \mathrm{L}$.

\subsubsection{MDA and NO Values}

MDA values were detected by thiobarbituric acid and NO values were detected by nitratase reductase using kits purchased from Jiancheng Institute of Biomedical Technology, Nanjing China. Standardization was conducted on an ultraviolet spectrophotometer (Bechmann DU640, USA) and the selected wavelengths were $532 \mathrm{~nm}$ for MDA and $550 \mathrm{~nm}$ for NO. Assay sensitivity is $0.1 \mathrm{mmol} / \mathrm{L}$ (MDA) and $0.1 \mu \mathrm{mol} / \mathrm{L}(\mathrm{NO})$.

\subsubsection{SOD and GSH-Px Activities}

SOD action was detected by xanthinoxidase and GSH-Px action was detected by chemical colorimetry with kits supplied by Jiancheng Institute of Biomedical Technology, Nanjing China. Standardization was conducted on an ultraviolet spectrophotometer and the selected wavelengths were $550 \mathrm{~nm}$ for SOD and $412 \mathrm{~nm}$ for GSH-Px. Assay sensitivity is $0.1 \mathrm{U} / \mathrm{mL}$ (SOD and GSH-Px).

\subsubsection{Histopathological Assay}

Pancreatic tissue samples fixed in $4 \%$ formaldehyde were gradually dehydrated in alcohol, hyalinized by dimethylbenzene, embedded in paraffin, sectioned at a thickness of $5 \mu \mathrm{m}$, adhered to sections prepared with poly-L-Lysine and stored at $4{ }^{\circ} \mathrm{C}$. Paraffin sections were deparaffinaged deparaffinated by dimethylbenzene, hydrated in gradient ethanol washed with distilled water and stained by Hematine-Eosin (HE) staining, that showed nuclei with a blue color and cytoplasm with a red color under light microscopy. Under a 400-fold light microscope, the average index of pancreatic B cells was calculated in five views selected randomly in each section from each animal. Index of pancreatic $\mathrm{B}$ cell in each view $=($ the number of pancreatic islets $\mathrm{B}$ cells/total number of cells $) \times 100$.

\subsubsection{Immunohistochemical Assay}

Rabbit anti-rat SOD and iNOS multi-clonal antibody, and strept actividin-biotin peroxidase complex $(\mathrm{SABC}) \mathrm{kit}$, diaminobenzidine $(\mathrm{DAB})$ kit were supplied by Wuhan Boster Biological Technology Co. Ltd. China. Paraffin-embedded sections were deparaffinaged in dimethylbenzene, hydrated successively in gradient ethanol and antigen was restored twice in a microwave oven. All procedures were strictly performed in accordance with the manufacturer's directions. Under a 
microscope, cells with brown granulation in cytoplasm or nucleus were considered to be positive. Negative control slides added 0.01 mol/L PBS (containing 1:200 blocking serum of non-immunized animals) instead of a primary antibody that has no immunological reaction. Under a $400 \times$ light microscope, five sections were randomly chosen from each experimental rat and observed in five views detected in islets. Absorbance values $(A)$ of each view were detected by a LEICA Qwin microgramme analytical system (Leica Company, Shanghai, China).

\subsection{Statistical Analysis}

SPSS17.0 software was used for statistical analysis. Data were expressed as mean \pm standard deviation $(\bar{x} \pm \mathrm{s})$. Multi-group comparison was made by analysis of variance (ANOVA) and Student's test and two-group comparison was by $t$-test. Values were considered to be significant when $P<0.05$.

\section{Conclusions}

This study suggested that kelp might enable the recovery of islet cell secretion function and reduce the FBG level by an antioxidant effect. Future research should focus on the hypoglycemic effect and the mechanism of kelp.

\section{Acknowledgements}

This study was supported by The National Natural Science Foundation of China (No. 40976085), CAS-Guangdong Provincial Joint Project (No 2009B091300086, 2010A090100023) and Key Projects in the National Science \& Technology Pillar Program during the twelve Five-Year Plan Period.

\section{Conflict of Interest}

This article does not compromise our adherence to Int. J. Mol. Sci. policies on sharing data and materials.

\section{References}

1. Shih, C.C.; Wu, Y.W.; Lin, W.C. Anti-hyperglycaemic and anti-oxidant properties of anoectochilus formosanus in diabetic rats. Clin. Exp. pharmacol. Physiol. 2002, 29, 684-688.

2. Surapaneni, K.M.; Venkataramana, G. Status of lipid peroxidation, glutathione, ascorbic acid, vitamin E and antioxidant enzymes in patients with osteoarthritis. Indian J. Med. Sci. 2007, 61, 9-14.

3. Bian, K.; Ke, Y.; Kamisaki, Y.; Murad, F. Proteomic modification by nitric oxide. Pharmacol. Sci. 2006, 101, 271-279.

4. Challa, S.R.; Akula, A.; Metla, S.; Gopal, P.N. Partial role of nitric oxide in infarct size limiting effect of quercetin and rutin against ischemia-reperfusion injury in normal and diabetic rats. Indian J. Exp. Biol. 2011, 49, 207-210. 
5. Aguilar, A.; Alvarez-Vijande, R.; Capdevila, S.; Alcoberro J, Alcaraz, A. Antioxidant patterns (superoxide dismutase, glutathione reductase and glutathione peroxidase) in kidneys from non-heart-beating-donors: Experimental study. Transpl. Proc. 2007, 39, 249-252.

6. Chung, S.S.; Kim, M.; Youn, B.S.; Lee, N.S.; Park, J.W.; Lee, I.K.; Lee, Y.S.; Kim, J.B.; Cho, Y.M.; Lee, H.K.; et al. Glutathione peroxidase mediates the antioxidant effect of peroxisome proliferator-activated receptor in human skeletal muscle cells. Mol. Cell Biol. 2009, 29, 20-30.

7. Tseng, CK. Algal biotechnology industries and research activities in China. J. Appl. Phycol. 2001, $13,375-380$.

8. Huang, L.; Guo, H.W.; Huang, Y.; Xue, K. The association of Lipoprotein lipase gene polymorphism with hyperlipidemia and dietary predisposition of obesity. Acta Nutr. Sin. 2007, 29, 228-231.

9. Chinese Pharmcopoeia Commission. Chinese Pharmacopoeia, Part I, 2000 ed.; Chemical Industry Press: Beijing, China, 2000; pp. 168-170.

10. Zhu, L.; Zhang, Q.; Wang, Y.F.; Kang, Y.Y.; Cen, Y.Z. Determination of polysaccharide from Ecklonia kurome. Chin. J. Mar. Drugs 2005, 24, 47-48.

11. Zhou, Q.F.; Li, M.Y.; Na, G.S.; Li, C.W. Progress in research of anti-tumor mechanisms of marine polysaccharides. Chin. Pharmacol. Bull. 2009, 25, 995-997.

12. Xu, X.Y.; Shuai, L.; Guo, Y.L.; Duan, D.L. Regulating effects and mechanism of Laminaria Japonica on serum lipid of hyperlipidemia in rats. Chin. J. Mar. Drugs 2009, 28, 1-4.

13. Shuai, L.; Xu, X.Y.; Guo, Y.L.; Duan, D.L. Study on the antioxidant effects of Laminaria japonica in hyperlipemia rats. Chin. J. Mar. Drugs 2010, 29, 1-4.

14. Wang, T.X.; Wang, T.X.; Pang, J.H. Study on the hypoglycemic and hypolipidemic effect of Laminarina japonica polysaccharides. Acta Nutr. Sin. 2007, 29, 99-100.

15. Ceriello, A.; Motz, E. Is oxidative stress the pathogenic mechanism underlying insulin resistance, diabetes, and cardiovascular disease? The common soil hypothesis revisited. Arterioscler. Thromb. Vasc. Biol. 2004, 24, 816-823.

16. Capellini, V.K.; Baldo, C.F.; Celotto, A.C.; Batalhão, M.E.; Cárnio, E.C.; Rodrigues, A.J.; Evora, P.R. Oxidative stress is not associated with vascular dysfunction in a model of alloxan-induced diabetic rats. Arq. Bras. Endocrinol. Metabol. 2010, 54, 530-539.

17. Van Guilder, H.D.; Bixler, G.V.; Kutzler, L.; Brucklacher, R.M.; Bronson, S.K.; Kimball, S.R.; Freeman, W.M. Multi-modal proteomic analysis of retinal protein expression alterations in a rat model of diabetic retinopathy. PLoS One 2011, 6, doi:10.1371/journal.pone.0016271.

18. Mircescu, G. Oxidative stress: An accomplice to uremic toxicity? Ren Nutr. 2006, 16, 194-198.

19. Lushchak, V.I. Free radical oxidation of proteins and its relationship with functional state of organisms. Biol. Chem. (Mosc.) 2007, 72, 809-827.

20. Zhou, T.; Zhou, K.K.; Lee, K.; Gao, G.; Lyons, T.J.; Kowluru, R.; Ma, J.-X. The role of lipid peroxidation products and oxidative stress in activation of the canonical wingless-type MMTV integration site (WNT) pathway in a rat model of diabetic retinopathy. Diabetologia 2011, 54, 459-468.

21. Chaiyasut, C.; Kusirisin, W.; Lailerd, N.; Lerttrakarnnon, P.; Suttajit, M.; Srichairatanakool, S. Effects of phenolic compounds of fermented thai indigenous plants on oxidative stress in streptozotocin-induced diabetic rats. Evid. Based Complement. Altern. 2011, 2011, 74-77. 
22. Kröncke, K.D.; Fehsel, K.; Suschek, C.; Kolb-Bachofen, V. Inducible nitric oxide synthesis-derived nitric oxide in gene regulation, cell death and cell survival. Int. Immunopharmacol. 2001, 1, 1407-1420.

23. Chapman, J.; Miles, P.D.; Ofrecio, J.M.; Neels, J.G.; Yu, J.G.; Resnik, J.L.; Wilkes, J.; Talukdar, S.; Thapar, D.; Johnson, K.; et al. Osteopontin is required for the early onset of high fat diet-induced insulin resistance in mice. PLoS One 2010, 5, doi:10.1371/journal.pone.0013959.

24. Soto, C.; Pérez, J.; García, V.; Uría, E.; Vadillo, M.; Raya, L. Effect of silymarin on kidneys of rats suffering from alloxan-induced diabetes mellitus. Phytomedicine 2010, 17, 1090-1094.

25. Silva, K.C.; Rosales, M.A.; Biswas, S.K.; Lopes de Faria, J.B.; Lopes de Faria, J.M. Diabetic retinal neurodegeneration is associated with mitochondrial oxidative stress and is improved by an angiotensin receptor blocker in a model combining hypertension and diabetes. Diabetes 2009, 58, 1382-1390.

26. Ouslimani, N.; Peynet, J.; Bonnefont-Rousselot, D.; Thérond, P.; Legrand, A.; Beaudeux, J.L. Metfrom in decreases intracellular production of reactive oxygen species aortic endothelial cells. Metabolism 2005, 54, 829-834.

27. Bottino, R.; Balamurugan, A.N.; Tse, H.; Thirunavukkarasu, C.; Ge, X.; Profozich, J.; Milton, M.; Ziegenfuss, A.; Trucco, M.; Piganelli, J.D. Response of human islets to isolation stress and the effect of antioxidant treatment. Diabetes 2004, 53, 2559-2568.

28. Liu, L.P..; Huang, J.; Chen, B.L.; Wang, J.; Li, M. Research on the hypoglycemic effect of marine alga Porphyridium cruentum in experimental diabetic mice. Chin. J. Mar. Drugs 2005, 24, 18-20.

29. Owu, D.U.; Antai, A.B.; Udofia, K.H.; Obembe, A.O.; Obasi, K.O.; Eteng, M.U. Vitamin C improves basal metabolic rate and lipid profile in alloxan-induced diabetes mellitus in rats. J. Biosci. 2006, 31, 575-579.

(C) 2012 by the authors; licensee MDPI, Basel, Switzerland. This article is an open access article distributed under the terms and conditions of the Creative Commons Attribution license (http://creativecommons.org/licenses/by/3.0/). 